Archive for

Organic Chemistry

Arkivoc 2020, part v, 108-118

\title{
ipso-Bromination of tert-butylcalix[4]arenes
}

\author{
Trégen M. Snayer, Sritama Bose, and Gareth E. Arnott* \\ Department of Chemistry and Polymer Science, Stellenbosch University, Private Bag X1, \\ Matieland, 7602, South Africa \\ Email: arnott@sun.ac.za
}

Received 09-30-2020

Accepted Manuscript 11-11-2020

Published on line 11-16-2020

\section{Abstract}

The ipso-bromination of calix[4]arenes using bromine has been investigated and provides a direct method to tetra-bromocalix[4]arene in a single step in excellent yield (>90\%). The method is also applicable to directly forming tribromocalix[4]arene in appreciable amounts ( $>60 \%)$. It was found during this study that a number of important reaction variables were very important for success, namely exclusion of light, temperature control, purity of starting material, solvent used and rate of bromine addition.
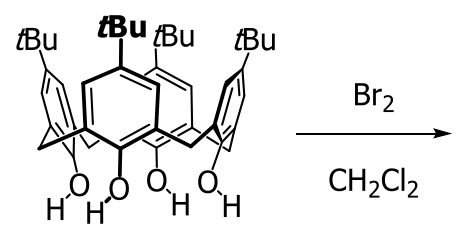

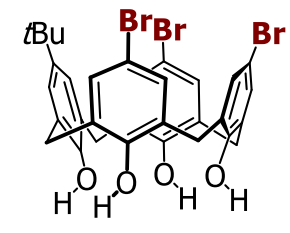

up to $60 \%$

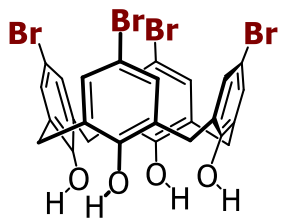

$90 \%$

Keywords: Ipso-bromination, calix[4]arene, bromine, regioselective 


\section{Introduction}

Brominated calix[4]arenes are important synthetic intermediates for calix[4]arene functionalisation, finding widespread use in the literature. ${ }^{1}$ A recent Reaxys ${ }^{\circledR}$ search (September 2020) revealed over 200 documents and 8 patents that report some form of aryl bromide calix[4]arene derivative. The reason for their importance is obvious: arylbromides are versatile functional groups, allowing for a wide variety of methods for functionalisation, particularly via metalation-coupling strategies. Of course, the methods for brominating a calix[4]arene on the upper rim are trivial in a synthetic sense. The para-positions are already perfectly activated for classic electrophilic aromatic substitution using either molecular bromine or $\mathrm{N}$-bromosuccinimide (NBS). However, calixarenes are synthesised from tert-butyl phenol, resulting in tert-butylcalixarenes as the product of the reaction. In order to introduce the bromine group, the tert-butyl group needs to be removed in a reverse Friedel-Crafts alkylation step with aluminium trichloride $\left(\mathrm{AlCl}_{3}\right)$ and a sacrificial phenol. ${ }^{2}$ There is one report in the literature by Varadarajan and co-workers, ${ }^{3}$ however, that describes the direct ipso-bromination of calix[4]-, calix[6]- and calix[8]arenes via their tert-butyl derivatives, which removes a whole synthetic step when pursuing aryl-brominated calixarenes. Whilst this paper has been frequently cited, no citing document has made use of the ipso-bromination method they report. We will address this in our Results and Discussion below.

The challenge in calix[4]arene chemistry is finding methods that selectively brominate one or more aromatic rings, so as to allow for diverse molecular architectures. The solutions which are routinely used mainly involve exploiting the difference in reactivity when the lower rim is partially reacted to form ester or ether functional groups, thus, leaving the unreacted phenolic groups to activate the upper-rim para-positions. This is currently a very neat method that allows access to mono-, ${ }^{4-8}$ distal-di- ${ }^{9-14}$ proximal-di, ${ }^{15-21}$ and tribromo ${ }^{22,23}$ calix[4]arenes (see Figure 1). It is also possible to form mono-bromo calix[4]arene by carefully adding slightly less than one equivalent of NBS to calix[4]arenes (Figure 2), ${ }^{24-28}$ a reaction we often employ in our own research. ${ }^{29-31}$ Unfortunately, small amounts of over-bromination products and unreacted starting material do complicate purification, which is non-trivial via column chromatography. Lastly, a distal-dibromo calix[4]arene is also readily available via selective removal of two distal bromine atoms from a tetra-bromo calix[4]arene (Figure 2). ${ }^{32}$
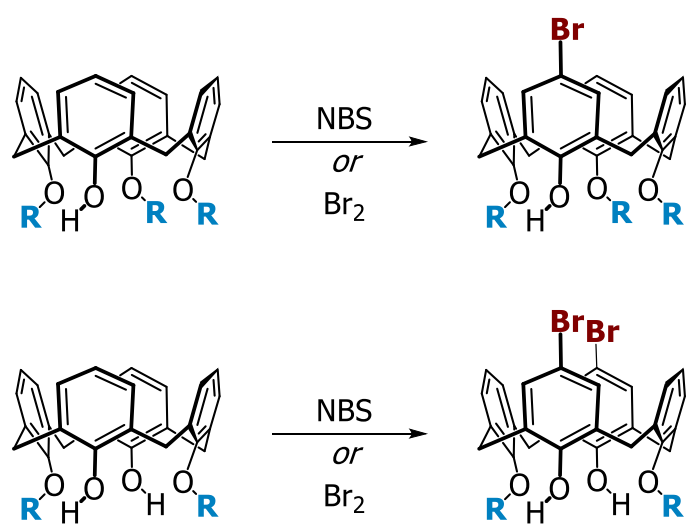

Figure 1. Two examples of bromination driven by lower-rim functionalisation ( $R=$ alkyl or acyl). 

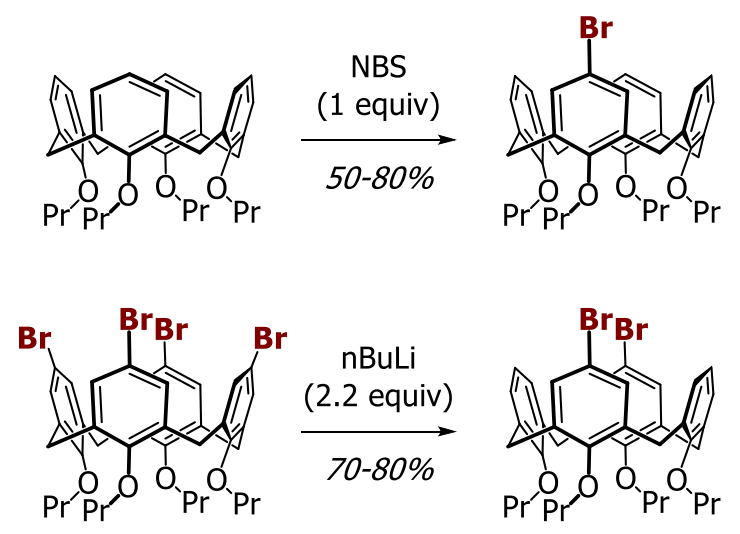

Figure 2. Two examples of selective bromine arrangement driven by stoichiometry.

During the course of our research on calix[4]arene platforms, we initiated a small study into the direct bromination of simple calix[4]arene starting materials. Herein, we report our findings that led us to developing a successful ipso-bromination of calix[4]arenes.

\section{Results and Discussion}

As part of our research program, we had required a small quantity of dibromo-di-tert-butylcalix[4]arene 3, which we planned to synthesise through the lower-rim functionalisation method shown in Scheme 1 Unexpectedly, when using a slight excess of bromine (three equivalents) instead of the more conventional NBS, we obtained a high yield of tribromocalix[4]arene 2, with concomitant removal of one of the propyl groups. Whilst this ipso-bromination step was unexpected, it drew our attention to the report by Varadarajan and co-workers mentioned in the Introduction. ${ }^{3}$ In their case, the reagents needed were either hydrogen bromide $(\mathrm{HBr})$ in acetic acid, or bromine $\left(\mathrm{Br}_{2}\right)$ with molecular iron $\left(\mathrm{Fe}^{0}\right)$ as a catalyst in a mixture of acetic acid and methylene chloride. We found their use of $\mathrm{HBr}$ to effect bromination to be rather unusual. Therefoe, we attempted this reaction ourselves, which, unsurprisingly, resulted in no reaction with starting material being fully recovered. Repeating their procedures with $\mathrm{Br}_{2}$ and $\mathrm{Fe}^{0}$ resulted in an intractable mixture that we could not characterise, nor could we observe any ipso-brominated intermediates. These results suggested why the reported ipso-bromination had never been used in the literature. Yet our own result suggested that ipsobromination might be a viable synthetic route under relatively mild conditions.

We, therefore, wondered what might happen if tert-butylcalix[4]arene $\mathbf{5}$ was itself simply treated with molecular bromine. An experiment was set up, with 1.5 equivalents of bromine stirring in chloroform at room temperature. TLC analysis revealed the formation of one new spot, although starting material remained. Therefore, another 1.5 equivalents of bromine were added, and the reaction was found to have gone to completion. After reaction work-up, the product was found to be monobromo-tri-tert-butylcalix[4]arene 6 (Scheme 2). This was deduced from the ${ }^{1} \mathrm{H}$ NMR spectrum that revealed a missing tert-butyl group, whilst the aromatic region was consistent with the signals expected for mono-ipso-substitution. Hi-res mass spectrometry also confirmed that the product had the predicted formula. As interesting as this reaction would be, however, these initial reactions always contained a small amount of starting material as a contaminant which could never be separated via chromatography. Repeating these experiments revealed an unfortunate precariousness to these initial results, with mixtures including dibrominated intermediates being obtained. 
The irreproducibility of this reaction spurred us to investigate what factors might be involved in order to develop a robust and reproducible result.
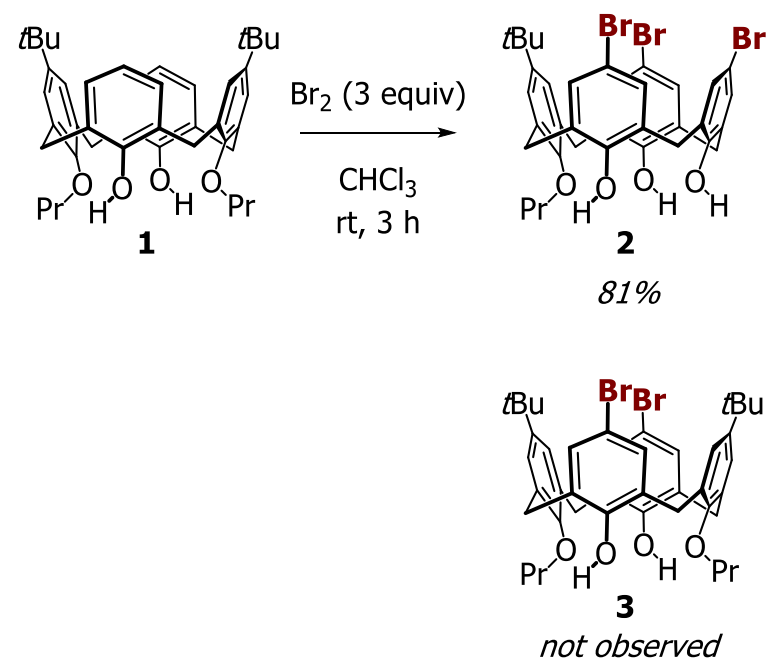

Scheme 1. Attempted formation of dibromo-di-tert-butylcalix[4]arene.
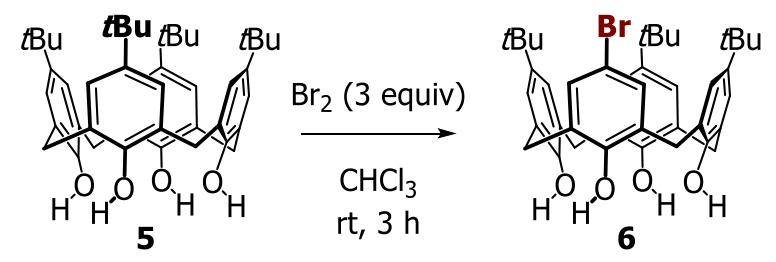

$78-80 \%$

Scheme 2. Preliminary finding of mono-ipso-bromination of tert-butylcalix[4]arene.

The first unusual observation was that the reaction essentially stopped giving ipso-brominated products when conducted in chloroform as a solvent (Scheme 3). Rather, trace amounts of spirodienone derivatives $7 \mathbf{a} / \mathbf{b}$ were obtained, which have been previously reported by Biali when using quaternary ammonium tribromide salts. ${ }^{33,34}$
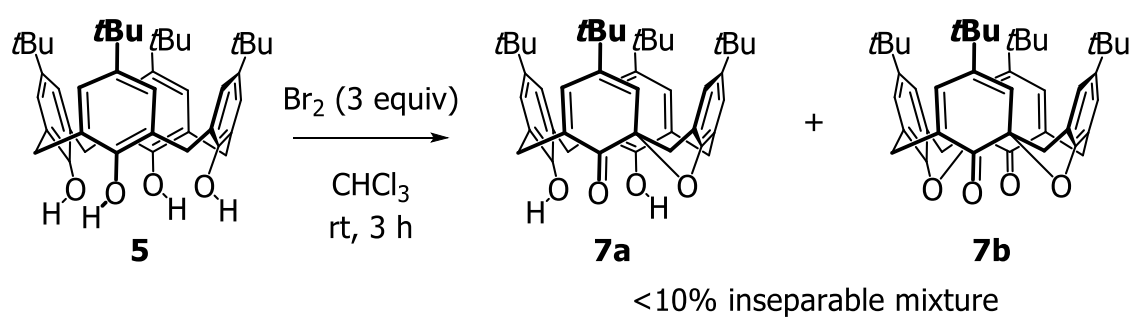

Scheme 3. Subsequent observation of spirodienone products when using chloroform as a solvent.

When we changed the solvent to methylene chloride, we, again, observed ipso-aryl-brominated products. Try as we might, however, we could never obtain appreciable quantities of the mono-brominated product 6, but rather mixtures, which included the other possible brominated products shown in Figure 3 . Fortunately, ${ }^{1} \mathrm{H}$ 
NMR spectroscopy was suitable for monitoring the percentage conversion of the various isomers (see ESI). What quickly became clear, however, was that even these reactions produced large variations in yields and product distributions.

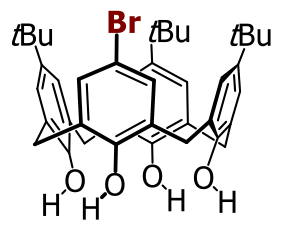

Mono 6

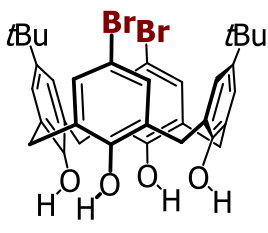

Distal 8

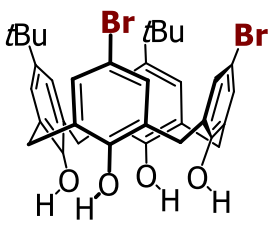

Proximal 9

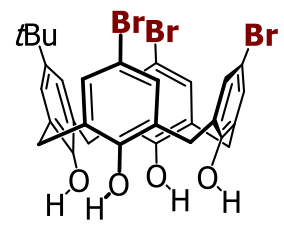

Tri 10

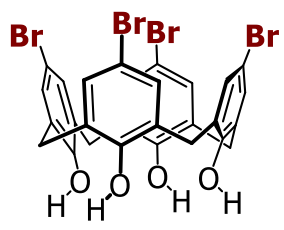

Tetra 11

Figure 3. The five different brominated calix[4]arenes observed during the course of this study.

In Table 1, entry 1 gives a snapshot of these differences, e.g., in one reaction, an $88 \%$ conversion to tribromocalix[4]arene 10 was observed, however, in another reaction, no tribromocalix[4]arene 10 was observed. We decided to look at controlling the temperature of the reaction since 'room temperature' is a somewhat nebulous variable when considering the changes in seasons and variations in lab conditions over the period of 24 hours. By conducting the reaction at a controlled temperature of $30{ }^{\circ} \mathrm{C}$ (Table 1 , entry 2 ), we observed a somewhat improved level of reproducibility, however, it was still far short of ideal. We then considered the fact that bromine is susceptible to homolytic cleavage by light, and, therefore, excluded light from the reaction using aluminium foil. This resulted in much more reproducible results (Table 1 , entry 3 ) which allowed us to attempt to find conditions to target specific brominated products. It should be noted, however, that, at this stage, only partial isolation of the products was possible; hence, our use of ${ }^{1} \mathrm{H}$ NMR spectroscopy to characterise the reaction outcomes. Starting material $\mathbf{5}$ and the mono-bromo derivative $\mathbf{6}$ always co-eluted, as did the dibromo derivatives $\mathbf{8}$ and $\mathbf{9}$. Tribromo $\mathbf{1 0}$ and tetrabromo $\mathbf{1 1}$ were also similarly difficult to separate.

Consideration of the entry 3 results suggested that the reaction was incomplete after 19 hours. Extending the reaction time to 48 hours (Table 1, entry 4) appeared to allow the reaction to reach an endpoint, the results of which are interesting in terms of accessing appreciable quantities of tribromocalix[4]arene 10, albeit, with partial contamination by the tetrabromo derivative 11. Fortunately, it was possible to obtain pure tribromo 10 via trituration when the tetrabrominated product 11 was in low amounts, (see Experimental section). The data also suggested an interesting possible kinetic effect, whereby the distal-8 and proximal-9 dibromocalix[4]arenes were produced at a similar rate, while the proximaldibromocalix[4]arene $\mathbf{9}$ was more rapidly converted to the tribromo-calix[4]arene 10. This is, of course, more of a phenomenological observation which would require further scrutiny to establish as fact. Adding four equivalents of bromine only increased the quantity of tetrabromo-calix[4]arene 11, much as would be expected (Table 1, entry 5). Reducing the number of equivalents to one and two (Table 1, entries 6 and 7 , respectively) shifted the distributions lower, however, not in a way that produced any appreciable amounts of mono-6 or di-bromo calix[4]arenes 8 or 9. 
Table 1. Optimization results: \% conversions are reported as a range of at least two runs

\begin{tabular}{|c|c|c|c|c|c|c|c|c|c|c|}
\hline Entry $^{a}$ & $\mathrm{Br}_{2}$ equiv. & $\operatorname{Temp}\left({ }^{\circ} \mathrm{C}\right)$ & Light & Time $(\mathrm{h})$ & $\begin{array}{l}\text { SM } \\
(\%)^{d}\end{array}$ & $\begin{array}{c}\text { Mono } \\
(\%)^{d}\end{array}$ & $\begin{array}{l}\text { Distal } \\
(\%)^{d}\end{array}$ & $\begin{array}{l}\text { Prox } \\
(\%)^{d}\end{array}$ & $\begin{array}{l}\text { Tri } \\
(\%)^{d}\end{array}$ & $\begin{array}{l}\text { Tetra } \\
(\%)^{d}\end{array}$ \\
\hline $1^{4}$ & 3 & RT & ambient & $20-24$ & $0-21$ & $0-54$ & $12-33$ & $0-23$ & $0-88$ & \\
\hline $2^{3}$ & 3 & 30 & ambient & 19 & $0-5$ & $0-16$ & $30-34$ & $13-30$ & $16-57$ & \\
\hline $3^{2}$ & 3 & 30 & excluded & 19 & & & $32-33$ & $9-18$ & $50-58$ & \\
\hline $4^{2}$ & 3 & 30 & excluded & 48 & & & $27-28$ & & 68 & $4-5$ \\
\hline $5^{2}$ & 4 & 30 & excluded & 48 & & & $11-16$ & & $68-70$ & $16-19$ \\
\hline $6^{2}$ & 1 & 30 & excluded & 48 & $43-47$ & $47-49$ & $6-8$ & & & \\
\hline $7^{2}$ & 2 & 30 & excluded & 48 & $1-2$ & $45-49$ & $26-28$ & $21-23$ & $0-5$ & \\
\hline $8^{3}$ & 10 & 30 & excluded & 24 & & & & & $0-16$ & $84-100$ \\
\hline $9^{1}$ & 10 & 30 & excluded & 72 & & & & & 24 & 76 \\
\hline $10^{2 b}$ & 10 & reflux & excluded & 24 & & & & & & 100 \\
\hline $11^{3 c}$ & 10 & $40^{e}$ & excluded & 24 & & & & & & 100 \\
\hline 12 & 10 & $60^{e}$ & excluded & 12 & & & & & $0-32$ & $68-100$ \\
\hline
\end{tabular}

${ }^{a}$ number of runs indicated by a superscript next to the entry number; ${ }^{b} 1$ run using 500 mg starting material; ${ }^{c}$ one run using $1 \mathrm{~g}$ of material. ${ }^{\mathrm{d}}$ conversions determined via ${ }^{1} \mathrm{H}$ NMR spectroscopy; values are the minimum and maximum values obtained over at least two runs. ${ }^{e}$ performed in a sealed tube.

Pushing the reaction towards forming the tetrabromo-calix[4]arene $\mathbf{1 1}$ was not as simple as anticipated from our earlier results. Logically, only four equivalents of bromine should be required, however, this never worked in our experiments. Rather, after some experimentation, we opted for 10 equivalents of bromine, which, in some, but not all cases, gave full conversion to the tetrabromo product in 24 hours (Table 1, entry 8). Extending the reaction time up to 72 hours still did not give consistent $100 \%$ reaction completion (Table 1 , entry 9). Only after heating the reaction under reflux for 24 hours did we obtain reproducible quantitative results (Table 1, entry 10), however, this had the negative effect of excess bromine escaping into the fume hood manifold. Therefore, the reactions were carried out in sealed vessels (Schlenk or microwave-type vessel) which gave a $100 \%$ conversion at $40{ }^{\circ} \mathrm{C}$ for 24 hours (Table 1, entry 11). Heating to higher temperatures and shorter reaction times, unfortunately, proved to be unsuccessful conditions for quantitative conversion (Table 1 , entry 12).

During the course of our study, it was found that a number of diverse factors were also important for success of the reaction, as follow:

Addition of bromine. It was found that bromine needed to be added dropwise (2-3 drops per second) using a $1 \mathrm{M}$ solution in methylene chloride. Adding the bromine quickly typically resulted in slower, incomplete reactions. Considering the total reaction time (at least 24 hours), this slow addition, in the order of minutes, is not readily explicable.

Bromine source. $\mathrm{N}$-Bromosuccinimide (NBS) resulted in no ipso-brominated products being obtained. Jiao and co-workers have also reported an oxidative bromination protocol employing $\mathrm{DMSO} / \mathrm{HBr},{ }^{35}$ which works on the debutylated calix[4]arene, and was confirmed by us. It failed, however, to do an ipso-bromination on the tertbutylcalix[4]arene $\mathbf{5}$. It should be noted that we did not attempt to use quaternary ammonium tribromide salts since these have been reported to give the spiro compounds mentioned above (

Scheme 3). ${ }^{33,34}$ Therefore, molecular bromine seems to be required. 
Calix[4]arene starting material. It was found that the reactions only worked successfully when the tertbutylcalix[4]arene starting material $\mathbf{5}$ had been recrystallized from toluene, which is the normal procedure found in the literature. This material is not pure tert-butylcalix[4]arene, but rather its toluene-inclusion complex. Synthetic protocols often accept that the crude tert-butylcalix[4]arene, obtained through the normal synthetic process, is sufficiently pure for subsequent reactions. In our case, employing the crude tertbutylcalix[4]arene always led to incomplete reactions. It was found that doping the reaction with one equivalent of toluene resulted in a better conversion compared to using the crude tert-butylcalix[4]arene alone, however, not to the extent that matched the conversions reported in Table 1 . We surmised that either the toluene-inclusion complex was important, or, additionally, perhaps some other minor impurity in the crude material was responsible for retarding the reaction. If we removed the toluene from the recrystallized material, however, and then doped the reaction with one equivalent of toluene, the reaction appeared to proceed normally. This suggested that, whilst the toluene was important, the problem was more likely an impurity in the crude tert-butylcalix[4]arene. One possible substitute candidate is acetic acid, which is used to wash the crude tert-butylcalix[4]arene. Unfortunately, it was found that adding acetic acid to the reaction severely retarded its progress, which also refers back to the problems we encountered in the article by Varadarajan, who reported the ipso-bromination in acetic acid and methylene chloride.

Solvent. The choice of solvent was important in that, essentially, the reaction failed unless it was conducted in chlorinated solvents. Table 2 highlights our findings in this regard.

Table 2. Notes on additional solvents examined

\begin{tabular}{|c|c|}
\hline Solvent & Notes \\
\hline Chloroform $\left(\mathrm{CHCl}_{3}\right)$ & $\begin{array}{l}\text { Heating up to } 70{ }^{\circ} \mathrm{C} \text { resulted in some reaction } \\
\text { being observed, but spirodienone formation was } \\
\text { an issue }\end{array}$ \\
\hline Carbon tetrachloride $\left(\mathrm{CCl}_{4}\right)$ & No reaction, even with heating to $70{ }^{\circ} \mathrm{C}$ \\
\hline 1,2-Dichloroethane (DCE) & $\begin{array}{l}\text { Reaction occurs well and is a reasonable } \\
\text { alternative to methylene chloride }\end{array}$ \\
\hline Acetone & $\begin{array}{l}\text { No reaction at } 30^{\circ} \mathrm{C} \text { after } 24 \mathrm{~h} \text {; starting material } \\
\text { insoluble }\end{array}$ \\
\hline Dimethylformamide (DMF) & No reaction at $30^{\circ} \mathrm{C}$ for $20 \mathrm{~h}$ \\
\hline Diethylether $\left(\mathrm{Et}_{2} \mathrm{O}\right)$ & $\begin{array}{l}\text { No reaction at } 30{ }^{\circ} \mathrm{C} \text { for } 24 \mathrm{~h} \text {; starting material } \\
\text { insoluble }\end{array}$ \\
\hline Tetrahydrofuran (THF) & $\begin{array}{l}\text { No reaction at } 30{ }^{\circ} \mathrm{C} \text { for } 24 \mathrm{~h} \text {; starting material } \\
\text { insoluble }\end{array}$ \\
\hline 2-Butanone (MEK) & $\begin{array}{l}\text { No reaction at } 30{ }^{\circ} \mathrm{C} \text { for } 24 \mathrm{~h} \text {; starting material } \\
\text { insoluble }\end{array}$ \\
\hline
\end{tabular}

Role of light and radicals. We have already discussed the fact that ambient light appeared to retard the ipsobromination reaction, which we suspected was due to radical formation. Increasing the intensity of the light with a halogen lamp only further retarded the reaction, suggesting that radicalization of the bromine was detrimental to the success of the reaction. If bromine radicals were being formed, however, it would be expected that radical brominated products would be observed. It is known that the tert-butylcalix[4]arene is resistant to benzylic bromination, unless the phenolic groups have been converted to ethers. ${ }^{36}$ Therefore, it $^{2}$ 
was not surprising to us that we never detected any such products. Nevertheless, the toluene that is included in the recrystallized tert-butylcalix[4]arene could undergo benzylic bromination, and these products were, indeed, detected in crude ${ }^{1} \mathrm{H}$ NMR spectra of reactions under ambient and halogen-lamp conditions. We also attempted to induce chemical radical formation with azobisisobutyronitrile (AIBN) whilst excluding light. Here, again, the reactions were retarded and benzyl bromide was detected. These results also suggest that the role of the toluene may be to act as a bromine radical trap in the reaction, which would, otherwise, have some retardation effect on the polar ipso-bromination process.

Larger calix[n]arenes. tert-Butylcalix[6]- and [8]arenes were preliminarily examined under our reaction conditions, but failed to fully brominate even when using vast excesses (30 equiv) of bromine, and extended reaction times at elevated temperatures. Brominated isomers were detected by mass spectroscopy, but were too difficult to isolate via chromatography.

\section{Conclusions}

We have investigated ipso-bromination as a method to form brominated calix[4]arenes, particularly for forming the tetra-bromocalix[4]arene $\mathbf{1 1}$ in one step. Furthermore, we have shown that other partially brominated isomers may be obtained, with the tri-bromocalix[4]arene $\mathbf{1 0}$ potentially being rather useful due to its unsymmetrical nature. It is important to note, however, that the reaction has quite a few parameters which must be carefully adhered to including: the absence of light, relatively slow addition of bromine, the use of methylene chloride or dichloroethane and tert-butylcalix[4]arene recrystallized from toluene. The methods reported by Varadarajan and co-workers using $\mathrm{HBr} / \mathrm{AcOH}$ were, not surprisingly, ineffective based on our work. Our findings were similar to the theoretically more likely reported results using $\mathrm{Br}_{2} / \mathrm{Fe}$ in acetic acid/methylene chloride. We could not reproduce these results, however, and our own experimentation pointed to poor reactivity in the presence of acetic acid. In future studies, it might be interesting to explore whether the ipso-bromination process might work on tert-butylcalix[4]arenes whose lower rims have been selectively protected, thus promoting regioselective bromination on the upper rim.

\section{Experimental Section}

General. All chemicals used in this investigation were obtained from either Aldrich or Merck. tertButylcalix[4]arene was synthesised using the published procedure. ${ }^{37}$ Dichloromethane was distilled under nitrogen from calcium hydride. Toluene and tetrahydrofuran were distilled under nitrogen from sodium wire/sand using benzophenone as the indicator. Purification of all other reagents, where necessary, was achieved using standard literature procedures. ${ }^{38}$

Thin layer chromatography (TLC) was performed on Macherey-Nagel DC-Fertigfolien ALUGRAM Xtra SIL G/UV 254 TLC plates. Visualization of compounds was achieved using a UV lamp $(254 \mathrm{~nm})$ after staining with a solution of cerium ammonium molybdate (CAM), followed by heating.

The ${ }^{1} \mathrm{H}$ NMR and ${ }^{13} \mathrm{C}$ NMR spectra were collected using Varian $300 \mathrm{MHz}$ VNMRS (75 $\mathrm{MHz}$ for ${ }^{13} \mathrm{C}$ ), Varian 400 $\mathrm{MHz}$ Unity INOVA (101 MHz for ${ }^{13} \mathrm{C}$ ) and Varian $600 \mathrm{MHz}$ Unity INOVA (151 MHz for ${ }^{13} \mathrm{C}$ ) NMR instruments using either deuterated chloroform $\left(\mathrm{CDCl}_{3}\right)$ or deuterated DMSO (DMSO- $d_{6}$ ) as solvent. All spectra were obtained at $25{ }^{\circ} \mathrm{C}$ and all chemical shifts $(\delta)$ are recorded in ppm. Chemical shifts were recorded using the residual $\mathrm{CDCl}_{3}$ (7.26 ppm in ${ }^{1} \mathrm{H}$ NMR and $77.2 \mathrm{ppm}$ in ${ }^{13} \mathrm{C} \mathrm{NMR}$ ) or DMSO-d $d_{6}$ (2.50 ppm in ${ }^{1} \mathrm{H}$ NMR and 39.5 
ppm in ${ }^{13} \mathrm{C}$ NMR) peaks. Mass spectrometry was carried out by the Central Analytical Facility (CAF) at Stellenbosch University using a Waters SYNAPT G2 QTOF mass spectrometer.

5,11,17-Tribromo-23-tert-butylcalix[4]arene (10). To a $200 \mathrm{~mL}$ Schlenk tube wrapped in foil, a magnetic stirrer bar, p-tert-butyl-calix[4]arene $(1.00 \mathrm{~g}, 1.54 \mathrm{mmol})$ and dichloromethane $(80 \mathrm{~mL})$ were added. Bromine $(1 \mathrm{M}$, $6.25 \mathrm{~mL}, 6.25 \mathrm{mmol}, 4.06 \mathrm{eq}$ ) was added, dropwise, to the flask and the contents warmed to $30{ }^{\circ} \mathrm{C}$. The mixture was then allowed to stir for 48 hours and was then quenched with sodium thiosulphate $(70 \mathrm{~mL})$. The organic layer was extracted, washed with $\mathrm{H}_{2} \mathrm{O}(120 \mathrm{~mL})$ and brine $(120 \mathrm{~mL})$, and excess solvent was removed under reduced pressure resulting in a white solid. The crude solid was stirred in a 3:1 DCM:EtOH mixture and then triturated with $\mathrm{H}_{2} \mathrm{O}$, giving $0.71 \mathrm{~g}(64 \%)$ of tribromo calix[4]arene as an off-white solid. ${ }^{1} \mathrm{H} \mathrm{NMR}(400 \mathrm{MHz}$, DMSO-d $\left.)_{6}\right) \delta$ ppm $7.39(\mathrm{~s}, 2 \mathrm{H}, \mathrm{ArH}), 7.37\left(\mathrm{~d}, 2 \mathrm{H},{ }^{4} J_{H H} 2.5 \mathrm{~Hz}, \operatorname{ArH}\right), 7.34\left(\mathrm{~d}, 2 \mathrm{H},{ }^{4} J_{H H} 2.5 \mathrm{~Hz}, \operatorname{ArH}\right), 7.19(\mathrm{~s}, 2 \mathrm{H}, \mathrm{ArH})$, 3.84 (br. s, 8H, $\left.\mathrm{ArCH} \mathrm{H}_{2} \mathrm{Ar}\right), 1.18\left(\mathrm{~s}, 9 \mathrm{H}, \mathrm{C}\left(\mathrm{CH}_{3}\right)_{3}\right) .{ }^{13} \mathrm{C} \mathrm{NMR}\left(101 \mathrm{MHz}, \mathrm{DMSO}-d_{6}\right) \delta \mathrm{ppm} 149.9,149.6,147.3,143.5$, 131.7, 131.0, 130.8, 130.7, 127.4, 125.7, 111.8, 111.7, 79.2, 33.8, 31.3, 30.6, 29.9. HRMS-TOF MS ESI-: $\mathrm{m} / z$ $[\mathrm{M}-\mathrm{H}]^{-}$calculated for $\mathrm{C}_{32} \mathrm{H}_{28} \mathrm{Br}_{3} \mathrm{O}_{4}:$ : 712.9538; found: 712.9507 .

5,11,17,23-Tetrabromocalix[4]arene (11). To a $200 \mathrm{~mL}$ Schlenk tube wrapped in foil, a magnetic stirrer bar, $p$ tert-butyl-calix[4]arene $(1.00 \mathrm{~g}, 1.54 \mathrm{mmol})$ and dichloromethane $(80 \mathrm{~mL})$ were added. Bromine $(1 \mathrm{M}, 15 \mathrm{~mL}$, $15 \mathrm{mmol}, 10 \mathrm{eq}$ ) was added, dropwise, to the mixture and the contents heated to $40{ }^{\circ} \mathrm{C}$. The mixture was the allowed to stir for 24 hours, after which it was quenched with sodium thiosulphate ( $150 \mathrm{~mL}$ ). The organic layer was extracted and washed with $\mathrm{H}_{2} \mathrm{O}(200 \mathrm{~mL})$ and brine $(200 \mathrm{~mL})$. Excess solvent was removed under reduced pressure resulting in a white solid in quantitative yield. Purification was achieved by stirring the solid in ethanol for $5 \mathrm{~min}$, followed by trituration with $\mathrm{H}_{2} \mathrm{O}$, to give $1.03 \mathrm{~g}(90 \%)$ of white powder. The characterization data collected for the compound compared well to the literature data. ${ }^{35}{ }^{1} \mathrm{H}$ NMR $\left(400 \mathrm{MHz}, \mathrm{DMSO}-d_{6}\right) \delta \mathrm{ppm}$ 7.30 (s, 8H, ArH), 3.78 (br. s, 8H, ArCH${ }_{2} \mathrm{Ar}$ ). ${ }^{13} \mathrm{C}$ NMR (101 MHz, DMSO-d 6 ) $\delta$ ppm 150.8, 131.1, 130.8, 111.1, 30.2. HRMS-TOF MS ESI-: $\mathrm{m} / z$ [M-H] $]^{-}$calculated for $\mathrm{C}_{28} \mathrm{H}_{19} \mathrm{Br}_{4} \mathrm{O}_{4}: 734.8017$; found: 734.7983 .

\section{Acknowledgements}

This work was supported by the National Research Foundation (Grant CPRR160428163281) and Stellenbosch University. TS thanks the DST/NRF for an MSc innovation scholarship and SB thanks the NRF for postdoctoral funding under grant CPRR160428163281. We also thank Dr J. Brand and Ms. E Malherbe (NMR spectroscopic service) and Dr M Stander and Mr M Taylor (mass spectroscopic service).

\section{Supplementary Material}

Spectra (HRMS and NMR), our NMR method for determining product ratios, and the raw data for experiments listed in Table 1 are included in the Supplementary Material in the online version.

\section{References}

1. A. Ivanova, E.; E. Prokhorova, P.; Y. Morzherin, Y. Mini. Rev. Org. Chem. 2016, 13 (4), 245-254. https://doi.org/10.2174/1570193X13666160428120003 
2. Gutsche, C. D.; Levine, J. A. J. Am. Chem. Soc. 1982, 104 (9), 2652-2653. https://doi.org/10.1021/ja00373a060

3. Kumar, S.; Chawla, H. .; Varadarajan, R. Tetrahedron Lett. 2002, 43 (39), 7073-7075. https://doi.org/10.1016/S0040-4039(02)01548-4

4. Hu, X.; Li, Y.; Yang, H.; Luo, Y. Tetrahedron Lett. 2006, 47 (42), 7463-7465. https://doi.org/10.1016/j.tetlet.2006.08.034

5. Daze, K. D.; Ma, M. C. F.; Pineux, F.; Hof, F. Org. Lett. 2012, 14 (6), 1512-1515. https://doi.org/10.1021/ol300243b

6. Surowiec, M.; Custelcean, R.; Surowiec, K.; Bartsch, R. A. Tetrahedron 2009, 65 (37), 7777-7783. https://doi.org/10.1016/j.tet.2009.07.006

7. Kliachyna, M. A.; Yesypenko, O. A.; Pirozhenko, V. V.; Shishkina, S. V.; Shishkin, O. V.; Boyko, V. I.; Kalchenko, V. I. Tetrahedron 2009, 65 (34), 7085-7091.

https://doi.org/10.1016/j.tet.2009.06.039

8. Hunter, R.; Koch, K.; Verblun, B. South African J. Chem. 1998, 51 (4), 200-206

9. Dondoni, A.; Ghiglione, C.; Marra, A.; Scoponi, M. J. Org. Chem. 1998, 63 (25), 9535-9539. https://doi.org/10.1021/jo980868w

10. Molenveld, P.; Engbersen, J. F. J.; Reinhoudt, D. N. Eur. J. Org. Chem. 1999, 1999 (12), 3269-3275. https://doi.org/10.1002/(SICI)1099-0690(199912)1999:12<3269::AID-EJOC3269>3.0.CO;2-V

11. Shokova, E. A.; Khomich, A. N.; Kovalev, V. V. Russ. J. Org. Chem. 2001, 37 (5), 612-619. https://doi.org/10.1023/A:1012423128245

12. Creaven, B. S.; Deasy, M.; Gallagher, J. F.; McGinley, J.; Murray, B. A. Tetrahedron 2001, 57 (42), 88838887.

https://doi.org/10.1016/S0040-4020(01)00872-9

13. Linnane, P.; James, T. D.; Shinkai, S. J. Chem. Soc. Commun. 1995, 24 (19), 1997-1998. https://doi.org/10.1039/C39950001997

14. Schühle, D. T.; Klimosch, S.; Schatz, J. Tetrahedron Lett. 2008, 49 (40), 5800-5803. https://doi.org/10.1016/i.tetlet.2008.07.128

15. Shirakawa, S.; Kimura, T.; Murata, S. I.; Shimizu, S. J. Org. Chem. 2009, 74 (3), 1288-1296. https://doi.org/10.1021/jo8024412

16. Yakovenko, A. V; Boyko, V. I.; Danylyuk, O.; Suwinska, K.; Lipkowski, J.; Kalchenko, V. I. Org. Lett. 2007, 9 (7), 1183-1185. https://doi.org/10.1021/ol0628513

17. Shimizu, S.; Moriyama, A.; Kito, K.; Sasaki, Y. J. Org. Chem. 2003, 68 (6), 2187-2194. https://doi.org/10.1021/jo0267293

18. Hüggenberg, W.; Seper, A.; Oppel, I. M.; Dyker, G. European J. Org. Chem. 2010, 2010 (35), 6786-6797. https://doi.org/10.1002/ejoc.201001108

19. Shirakawa, S.; Shimizu, S. European J. Org. Chem. 2009, 2009 (12), 1916-1924. https://doi.org/10.1002/ejoc.200801288

20. Awada, M.; Jeunesse, C.; Matt, D.; Toupet, L.; Welter, R. Dalton Trans. 2011, 40 (39), 10063-10070. https://doi.org/10.1039/c1dt10375j

21. Vysotsky, M. O.; Tairov, M. O.; Pirozhenko, V. V; Kalchenko, V. I. Tetrahedron Lett. 1998, 39 (33), 60576060. https://doi.org/10.1016/S0040-4039(98)01246-5

22. Gagnon, J.; Vézina, M.; Drouin, M.; Harvey, P. D. Can. J. Chem. 2001, 79 (10), 1439-1446. 
https://doi.org/10.1139/v01-161

23. Matvieiev, Y.; Solovyov, A.; Shishkina, S.; Shishkin, O.; Katz, A.; Boiko, V.; Kalchenko, V. Upper-Rim Calixarene Phosphines Consisting of Multiple Lower-Rim OH Functional Groups: Synthesis and Characterisation. Supramolecular Chemistry. Taylor \& Francis December 2, 2014, pp 825-835. https://doi.org/10.1080/10610278.2014.88251

24. Ikeda, A.; Yoshimura, M.; Lhoták, P.; Shinkai, S. J. Am. Chem. Soc. Perkin Trans. 1996, 1 (16), 1945-1950. https://doi.org/10.1039/p19960001945

25. Stastny, V.; Lhoták, P.; Stibor, I.; König, B. Tetrahedron 2006, 62 (24), 5748-5755. https://doi.org/10.1016/j.tet.2006.03.083

26. Stejskal, F.; Cuřínová, P.; Lhoták, P. Tetrahedron 2016, 72 (5), 760-766. https://doi.org/10.1016/j.tet.2015.12.037

27. Kundrat, O.; Kroupa, J.; Böhm, S.; Budka, J.; Eigner, V.; Lhotak, P. J. Org. Chem. 2010, 75 (24), 8372-8375. https://doi.org/10.1021/jo1013492

28. Holub, J.; Eigner, V.; Vrzal, L.; Dvořáková, H.; Lhoták, P. Chem. Commun. 2013, 49 (27), 2798-2800. https://doi.org/10.1039/c3cc40655e

29. Applewhite, M. J.; Haynes, D. A.; Arnott, G. E. Supramol. Chem. 2016, 28, 475-484. https://doi.org/10.1080/10610278.2015.1121268

30. Herbert, S. A.; Arnott, G. E. Org. Lett. 2010, 12 (20), 4600-4603. https://doi.org/10.1021/ol101909f

31. Herbert, S. A.; Van Laeren, L. J.; Castell, D. C.; Arnott, G. E. Beilstein J. Org. Chem. 2014, 10 (1), $2751-2755$. https://doi.org/10.3762/bjoc.10.291

32. Larsen, M.; Jørgensen, M. J. Org. Chem. 1996, 61 (19), 6651-6655. https://doi.org/10.1021/jo9609440

33. Litwak, A. M.; Biali, S. E. J. Org. Chem. 1992, 57 (7), 1943-1945. https://doi.org/10.1021/jo00033a001

34. Litwak, A. M.; Grynszpan, F.; Aleksiuk, O.; Cohen, S.; Biali, S. E. J. Org. Chem. 1993, 58 (2), 393-402. https://doi.org/10.1021/jo00054a023

35. Song, S.; Sun, X.; Li, X.; Yuan, Y.; Jiao, N. Org. Lett. 2015, 17 (12), 2886-2889. https://doi.org/10.1021/acs.orglett.5b00932

36. Klenke, B.; Näther, C.; Friedrichsen, W. Tetrahedron Lett. 1998, 39 (49), 8967-8968. https://doi.org/10.1016/S0040-4039(98)02056-5

37. Gutsche, C. D., Iqbal, M. Org. Synth. 1990, 68, 234. https://doi.org/10.15227/orgsyn.068.0234

38. Armarego, W. L. F.; Chai, C. Purification of Laboratory Chemicals, 4th ed.; 4th Edition, Reed Educational \& Professional Publishing Ltd: Oxford, 1996.

https://doi.org/10.1016/C2009-0-26589-5 